\title{
Intention to Reserve Food During COVID-19 Pandemic Among Bangladeshi Internet Users: Based on Theory of Planned Behaviour
}

\author{
MD Nafiul Alam Khan ${ }^{1 *}$ \\ ${ }^{1}$ Khulna University, Bangladesh \\ * Corresponding author: MD Nafiul Alam Khan E-mail: nafiul.nipun95@gmail.com ORCID: 0000-0002-6059-4571 \\ Received: 9 April 2020 Accepted: 21 May 2020
}

\begin{abstract}
Introduction: The COVID-19 is probably the most terrible pandemic in the world, because there is no approved vaccine or treatment for this rapidly spreading disease. Most of the country is locked down for reducing spreading disease. Due to lockdown situations people are afraid and confused for getting basic food available at hand.

Objective: The purpose of this study is to investigate the expanded theory of planned behaviour model and adding risk perception variables for intention to reserve food during covid-19 pandemic situation among Bangladeshi internet users.

Material and Methods: A total of 192 consumers living in Bangladesh actively interested in a cross-sectional web-based survey. A standardized questionnaire was generated using Google Forms and a link was shared through authors' platforms. This sample comprised 110 (57.3\%) males and 82 (42.7\%) females. Collected information was statistically analyzed using structural equation modelling assessment.
\end{abstract}

Results: The estimation process assesses the precision and validity of the variables. Cronbach's alpha and composite reliability (Pc) was used to test the durability of the design. However, this study found Cronbach's alpha and Pc between 0.842 to 0.730 and 0.864 to 0.744 . Moreover, Convergent validity is effectively identified in the findings of the analysis. Therefore, the calculation concept of the analysis has been tested successfully.

Conclusion: In this analysis, we see that the stronger the risk perception of consumers, the greater the attitude of consumers to buy reserve products. This proof that high-risk awareness, in the case of a COVID-19 pandemic or others pandemic situation, can lead to the purchasing of goods that are lack of patience or common sense. The paper presented a new perspective on the negative consequences of risk perception among Bangladeshi internet users.

Keywords: COVID-19, reserve food, intention, pandemic, Bangladesh

\section{INTRODUCTION}

New coronavirus disease 2019 (COVID-19) is by far the most severe viral infection that has triggered a major human life tragedy worldwide. COVID-19 has the same veiled RNA structure that resembles SARS-CoV-2 and MERS-CoV but is more pest-like $[1,2]$. The basic concept of infection with COVID-19 is that it spreads by direct mucus contact with the breath, swallowing, and salivary abscess of an infected

@ 2020 by the authors; licensee EJMETS by Bastas, UK. This article is an open access article distributed under the terms and conditions of the Creative Commons Attribution License (http://creativecommons.org/licenses/by/4.0/). 
person who has been able to survive on hands, objects, or surfaces for the past nine days $[3,4]$. Following the global pandemic of COVID-19, which has infected most areas of the world with high mortality rates reported in Italy, Spain, the United States of America, France, the United Kingdom and many parts of Europe and Africa, the death toll continues to increase [5]. 40 coronaviral mutations have been detected by scientists in Iceland in order to help the immediate need to contain the fear of the uncontrolled virus, increasing in a continuously growing amount of cases and deaths recorded in various countries every day. On 11 March 2020, the World Health Organization announced a global pandemic after the outbreak spread through countries across the world and killed 4,200 people [6]. About three weeks later, on 30 March, coronavirus COVID-19 infected 199 countries around the world on six continents and 2 international carriers, with 722,202 reported cases, and the death rate rose more than 8 times, or 33,976 people, although the figure continued to grow exponentially [7]. Just like all the other countries, Bangladesh is also at the frontline of the COVID-19 crisis as the first COVID-19 patient was detected on 7 March 2020 (10) [8]. The epidemic of COVID-19 in Bangladesh has been growing day by day, with 38 deaths out of a total of 803 reported cases recorded until 13 April 2020 [9].

As no treatment or vaccination has yet been created for COVID-19 infection, the medical community and the authorities are finding expertise and details on the short-and long-term handling of present and possible pandemic crises. The food sector and its stakeholders are also in the spotlight, as food is necessary for human survival and can not be blocked. A major pandemic that has triggered more than $25 \%$ reduction in labor supply may contribute to substantial food shortages across the globe [10]. This underlines the value of resilience of the food chain of order to avoid or raising the occurrence of food and safety shortages in the future. In the current age of the COVID-19 pandemic, customers are projected to rapidly try goods to improve their immune systems in the future. Public health, Environmental protection with the Globe Society Lockdown, Security of Food Systems [11]. The recovery of useful compounds from food waste is a significant task for fieldrelated scientists, but commercial application is a dynamic method, based on many factors that need to be addressed [12]. Glucosinolates have the potential to be used in the food industry as food additives to improve the organoleptic characteristics of food products and as antimicrobials to facilitate the inactivation of foodborne pathogens when combined with conventional processing and nonconventional preservation technologies [13]. Quite apart from the fact that it appears like we are a long way from this stage, the industry and customers are seeking custom-made processes and goods, which should push food producers to adopt the above technology sooner or later. That is expected to happen only with the handling of by-products, which is a part of the agriculture and associated food industry [14].

While the national plan to shield individuals from medical retreats is well underway and seems to have secured the first fight to contend with the pandemic. Around the same moment, many companies face challenges in managing these threats, and many facets of the economy and culture around the world are shifting quickly in reaction to the disruption in operations; utilities and development have been halted, and many enterprises are going in a risky path towards bankruptcy [15]. Fearing an epidemic, many citizens rushed to stores, urban markets, and convenience shops to purchase hoarding food, buying so many that food stalls and other basic products were easily empty and scarce, even though the government has continuously communicated that there will still be a supply of food for all residents, including in the case of a prolonged lockdown. Members in a community who do not have a stable income and constantly have everyday spending activities may often be distressed when stocks are exhausted and that may add to the possibility of unrest in the community. Multiple previous researches have shown that analyzing the actions of individuals in social structure under conditions of social uncertainty is important both economically and sociologically [16-19]. There is also an immediate need for scientists to consider the public reaction to pandemic events such as COVID-19 in this situation. The goal of this paper is to investigate the effect of the ongoing pandemic of coronavirus disease in 2019 on the intentions of Bangladeshi citizens in food storage. The goal of the research was to explore a theoretical model of the effect of Risk Perception of COVID-19 on factors influencing the intention to buy food following the Theory of planned behaviour (TPB) model of Icek Ajzen (1991) Thus it is used in practice to avoid national economic damages from the unnecessary handling of food by individuals. The paper is both a theoretical framework for policymakers to recognize threats posed by panic-related actions and collapse impacts on markets, and to provide countries with an anti-crisis economic policy option.

\section{LITERATURE REVIEW AND RESEARCH HYPOTHESES}

In circumstances of the Coronavirus disease outbreak, the majority of young mothers reported significant disease- 
related fears, and this fear ranks third in the socialpsychological fear rankings of this sample. In modern culture, with the aid of news media, everybody consumes knowledge that has taken place across the globe. Knowledge also has a derogatory connotation. Danger distribution environments, risk indicators and their representation in mass consciousness are regarded [20]. Educational institutes are taking online classes for the fear of mass outbreak across the country. Like Philippines, higher study of worldwide mostly affected by COVID-19 pandemic as there is a fear of outbreak. So that thousands of school, college and University are closed due to maintain the social distancing $[21,22]$. Digital learning and various online class systems are opened to cope up with this situation, but the economical side is decreasing day by day $[23,24]$. Online journalism took a great part of giving information about COVID-19 situation as the people get modified and aware by the information from online platform [25]. It is essential that customers are well conscious of the dangers of a pandemic, that they may affect the views of others around them regarding the dangers they face and that they also support their approach to coping with potential threats to the environment [26].

Ajzen (1991) introduced a theoretical framework for the investigation of the factors that influences behavioral choices. This theory has been successfully used to investigate behaviors in many previous studies such as leisure choice [27], driving violations, shoplifting and dishonest actions. This theory was developed based on the theory of reasoned action by Ajzen and Fishbein, (1980), where it is assumed that people have a moral foundation for their actions to understand the consequences of their actions $[28,29]$. In theory of planned behavior (TPB), it is assumed that the immediate predictor of actions is the desire of the person to conduct or not to perform the behavior. This is dependent on the following three factors:

1. Attitude, favorable or unfavorable assessment of actions by the person.

2. The subjective norm, the interpretation of the individuals of social pressure to perform or not to perform the behavior.

3. Perceived power, understanding of the individual's capacity to conduct behavior.

\section{Risk Perception (RP)}

People are relying on their feelings to substitute other facts, such as the actual numerical danger. In this scenario, those with a more negative outlook during a pandemic may perceive a greater risk than if they had fewer negative emotions. In the case of COVID-19, as negative emotions increase, people may try and/or consider more negative COVID-19 information than others [30]. Emotion also serves as a strong motivator of actions, such as socially isolating, washing hands, but also reserving resources, and harsh care. Past studies have seen risk perception as a significant factor affecting purchasing decisions or purchasing intentions $[31,32]$. Risk perception arises when food consumers intend whether it is safe or unsafe for physical health before making a buying decision of certain products [33]. In addition, when a commodity is purchased, the attitude of the user is often influenced by the perception of risk factors such as financial risks, functional risks, social risks, psychological risks and perceived overall risk [34]. During the COVID-19 pandemic, people thought that health and safety risks, price threats and product quality risks were all small and perceived a high risk of contamination or lockdown, so their perception of danger might be in the same direction as purchasing a reserve. Therefore, we construct a hypothesis:

$\mathbf{H}_{1}$ : Risk perception has a positive impact on customer behaviour in the food reservation strategy.

Risk perception is considered to be the nature to which mental awareness perceives factors related to potentially toxic behaviors or technologies which decide the risk decisions of individuals [35]. The value of risk management for the economy was examined quite early, after Knight's (2012) [36], research hundreds of years ago. A variety of experiments have been performed to date to understand the effect of risk perception on actions in life, particularly customer behaviour. The calculation of the level of risk differs for each situation and the particular decision-making mechanism is defined by the degree of expense, profit, level of loss and level of risk tolerance [37]. Past research has established Risk Perception as a significant factor impacting purchasing decisions or purchasing intentions [38]. So, we hypothesize that $\mathrm{H}_{3}$ as follows:

$\mathbf{H}_{3}$ : Risk perception has a significant effect on the expected actions of customers in the food reserve strategy.

\section{Attitude (AT)}

Attitude to behavior is defined by clear confidence in their behavior (behavioral beliefs), which is the conviction that a person has an impact on behavior and judgment or performance [39]. In Bangladesh, evaluation of attitudes towards coronavirus disease-2019 (COVID-19) among citizens. They showed good knowledge and a positive attitude [40]. Thus, Hypothesis ${ }_{4}$ indicates that: 


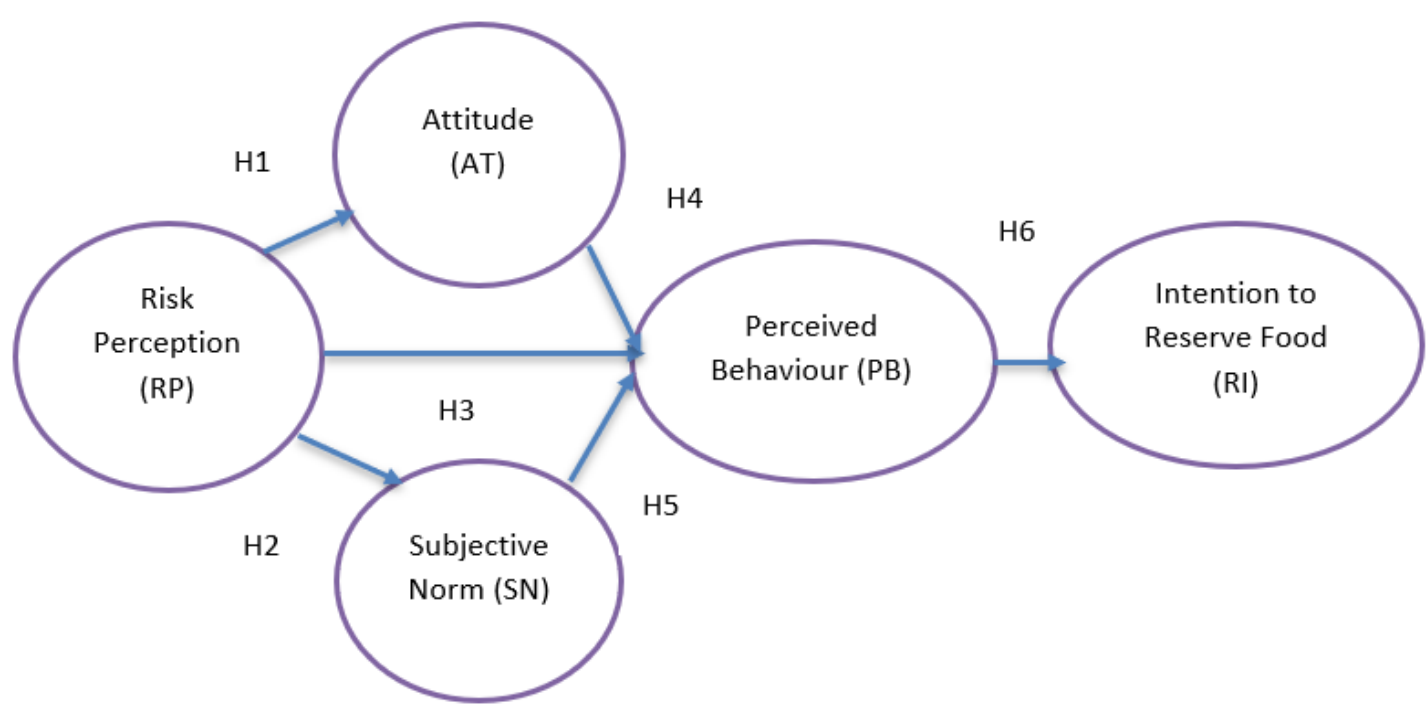

Figure 1. Expected Model

$\mathbf{H}_{4}$ : The attitude has a positive impact on the expected attitude of customers in the strategy to reserve food.

\section{Subjective Norm (SN)}

People's preferences are affected by social expectations as a subjective norm: what they see others do or approve / disapprove. Normative impact happens as individuals comply with social recognition and become identified with more public than private adherence $[41,42]$. Despite the fact that individuals are impacted by view of standards, their evaluations of conduct are much of the time off base. For instance, they think little of wellbeing advancing practices (e.g., handwashing [43] and overestimate undesirable practices. Changing practices by rectifying misperceptions is likely better accomplished by open messages strengthening wellbeing advancing standards (e.g., normal commitment in social removing and hand-washing) as opposed to featuring outrageous/exceptional practices (e.g., alarm purchasing, youthful grown-ups gathering). If group differences yield differing rates of adherence to health-protective practices, differing rates of infection / mortality and higher viruscontaining difficulties are predicted. Messages that have ingroup norms templates (e.g. members of the community) can also be more successful. Hence, $\mathrm{H}_{2}$ and $\mathrm{H}_{5}$ are hypothesized as:

$\mathbf{H}_{\mathbf{2}}$ : Risk perception has a positive effect on the Customer Subjective Norm in the Food Reserve Program.

$\mathbf{H}_{5}$ : The subjective norm has a favorable impact on the expected attitude of customers in the food reserve strategy.

\section{Perceived Behavior (PB)}

Perceived Behavior explains buyer aggregating subject to up close and personal comprehension and feeling choices and these choices are consistently dictated by mental elements, for instance, [44], worries over depletion; deficiency of items; apprehension about an individual's money related breaking point that can't meet the need situation when the inadequacy occurs; and explicitly the frenzy brought about by "group conduct". Exactly when frenzy spread all over the place, clients never again act sensibly, they, for the most part, need to buy more than they need, the stock of items will be lopsided, various people can't buy in light of the void of product in selling places. The more they become alarmed, the more intellectually denied it is in the market. In this manner, the money related weight is on everyone in view of the noteworthy cost of reserving when social distress creates. So, we give Hypothesis 6 as follows:

$\mathbf{H}_{6}$ : Perceived Behavior favorably affects the consumer's decision to reserve food. From a theoretical basis, the research proposes the expected research model shown in Figure 1.

\section{MATERIALS AND METHODS}

\section{Design of the Study}

The cross-sectional web-based analysis was conducted amongst Bangladeshi Internet users from 20 April to 25 April 2020. As the country maintains a lockdown and a limit on travel to mitigate the spread of COVID-19, it was therefore the best approach available to authors to perform a study using a convenient web-based survey. A Likert-scale style survey was used to discover the determinants measured from (1) "Strongly disagree" to (5) "Strongly agree". The questionnaire link was shared through Facebook, email, WhatsApp and so on. The Cronbach alpha for the questionnaire is 0.62 , suggesting that the questionnaire is a 
Table 1. Respondent Demographic characteristics

\begin{tabular}{|c|c|c|}
\hline Age-Group & Frequency & Percentage (\%) \\
\hline $18-29$ & 61 & 31.77 \\
\hline $30-39$ & 84 & 43.75 \\
\hline $40-49$ & 45 & 23.44 \\
\hline Over 50 & 2 & 1.04 \\
\hline Total & 192 & 100 \\
\hline Highest education level & Frequency & Percentage (\%) \\
\hline Up to HSC & 25 & 13.02 \\
\hline Honors & 150 & 78.13 \\
\hline Masters & 17 & 8.85 \\
\hline Total & 192 & 100 \\
\hline Income & Frequency & Percentage (\%) \\
\hline Under 5k Taka & 30 & 15.63 \\
\hline From 5K to under 15k & 110 & 57.29 \\
\hline From 15k to under 30k & 43 & 22.40 \\
\hline Over 30k Taka & 9 & 4.69 \\
\hline Total & 192 & 100 \\
\hline
\end{tabular}

legitimate and accurate instrument for determining the purpose of the analysis. The study contained questions about the status of the determinants that had an effect on the decision to store food during the COVID-19 pandemic. The eligibility requirements for participating in the survey were to be a Bangladeshi Internet user aged 18 years or older, to recognize the intent of the study and to be able to participate on a voluntary basis. Respondents were chosen using convenience web-based approaches with a sample size of 192 consumers residing in Bangladesh. This sample comprised 110 (57.3\%) males and 82 (42.7\%) females. Their demographic characteristics such as ages, income, and qualification displayed in Table 1.

\section{Structural Model Assessment}

Structural equation modeling is a multivariate statistical analysis technique that is used to analyze structural relationships. This approach is a mixture of factor analysis and multiple regression analysis and is used to evaluate the relational association between observable variables and latent constructs. The investigator likes this approach because it measures multiple and interrelated dependency in a single study. Two types of variables are used in this analysis: independent variables and dependent variables. Endogenous variables are equivalent to dependent variables and are equal to the independent variable. An advantage of SEM, is its capacity to estimate and test the relationships among constructs. SEM will easily encourage counseling psychologists to address more complicated testing questions and to evaluate multivariate models in a single sample. The analysis of possible theories for behavioral phenomena is fundamental to the scientific investigation process. Recent work has demonstrated the
Table 2. The reliability and validity

\begin{tabular}{|c|c|c|}
\hline Construct & Cronbach's Alpha & Composite Reliability (Pc) \\
\hline AT & 0.842 & 0.850 \\
\hline RI & 0.821 & 0.864 \\
\hline PB & 0.806 & 0.829 \\
\hline RP & 0.730 & 0.744 \\
\hline SN & 0.811 & 0.825 \\
\hline
\end{tabular}

effectiveness of Knowledge Theoretic model selection parameters for partial least square structural equation models (PLS-SEM) which have been widely disseminated in a number of fields [45].

After checking the model for the datasets to investigate the intention to reserve food during the COVID-19 pandemic. The dataset has five components of 192 consumers living in Bangladesh who thoroughly use the internet. The data was analyzed using smartpls 3.0 trial version software. Cronbach's alpha $(\alpha)$ was used to test the scales reliability and validity. Structural Equation Model (SEM) used to test the concept of the model's hypothesis $[46,47]$. The alpha coefficient of Cronbach's and Composite Reliability (Pc) are greater than 0.6 will ensure the precision of the measure. This technique might influence a variety of autonomous elements, in any case where there is multicollinearity. PLS could be used as a regression tool, estimating at least one ward component from a ton of at least one free component, or it might very well be done as a concept method.

\section{RESULTS}

\section{Measurement Model}

The estimation process assesses the precision and validity of the variables. Cronbach's alpha and composite reliability (Pc) was used to test the durability of the design [47]. According to Hair Jr et al. [46], Cronbach's alpha and Pc values should be more than 0.60 . However, this study found Cronbach's alpha and Pc between 0.842 to 0.730 and 0.864 to 0.744 . Moreover, according to Hair Jr et al. $[46,47]$ Convergent validity is effectively identified in the findings of the analysis. Therefore, the calculation concept of the analysis has been tested successfully. The results of Cronbach's alpha, Pc can be seen in Table 2.

Using the PLS formula, the analysis tested the systemic model to render the final statement on acceptance and rejection of the hypothesis. The route coefficient used to test the interaction between the frameworks. In other words, a partial least square (PLS) may be a statistical model that can accommodate one or more dependent variables with a collection of one or more independent variables, or can be applied as a direction model. As a product of the significance 
Table 3. The direct relationship between construct

\begin{tabular}{|c|c|c|c|c|c|}
\hline Hypothesis & $\boldsymbol{\beta}$ & SD & T Values & P Values & Decision \\
\hline AT $->$ PB & 0.551 & 0.113 & 6.156 & 0.000 & Acceptance \\
\hline PB $->$ RI & 0.804 & 0.043 & 27.429 & 0.000 & Acceptance \\
\hline RP $->$ AT & 0.621 & 0.071 & 8.675 & 0.000 & Acceptance \\
\hline RP $->$ PB & 0.181 & 0.051 & 2.818 & 0.001 & Acceptance \\
\hline RP $->$ SN & 0.441 & 0.063 & 7.422 & 0.001 & Acceptance \\
\hline SN $->$ PB & 0.501 & 0.091 & 5.818 & 0.001 & Acceptance \\
\hline
\end{tabular}

Table 4. Model fit

\begin{tabular}{|c|c|}
\hline Indicator & Saturated model \\
\hline SRMR & 0.063 \\
\hline d_ULS & 0.604 \\
\hline d_G & 0.620 \\
\hline Chi-Square & 531.23 \\
\hline NFI & 0.891 \\
\hline
\end{tabular}

amount obtained from the bootstrapping test, the t-value would be greater than 1.96 at the significance level of 0.05 . The present research started bootstrapping at 5000 subsamples and collected the findings; the findings can be found in Table 3.

Results in Table 4 showed that Chi-square $=531.23$ was significant at $0.05(p=0.00)$. SRMR (standardized root means square residual) was a calculation of the estimated fit of the proposed study model. Through default, the layout worked well while the SRMR was less than 0.08. The findings of the study in Table 4 revealed that the model had SRMR indices $=0.063<0.08$. As a consequence, the initial study model was well fit for review data.

\section{DISCUSSION}

From the most current knowledge available to date, this is a significant study to investigate Intention to Reserve Food During COVID-19 Pandemic in Bangladesh. The study is dominated by the male (68.7\%) and well educated (68.9\%) respondents where the overall correct knowledge is $63.3 \%$ and complete practice prevalence is $76.9 \%$. Two classes of citizens with two contrasting views will emerge in the pandemic exacerbated by COVID-19. Many individuals are very thoughtless with alarming details regarding the occurrence with dangerous disease, unaware of epidemic alerts. This community of citizens will not pay heed to the possible effects to themselves and their families, and that is the major source of the quickly growing epidemic, with a rising number of people contaminated and dying every day in many countries across the world. The remaining community has a terrifying mentality and still deliberately prevents future damages despite the opportunity for constructive awareness. Bangladesh is an emotional nation as an uncontrollable emotion of danger and fear and could have aggressive activities such as the accumulation of all capital to buy food, medication, and products. As a consequence, panic shopping would intensify concerns about the flu, increasing product prices beyond reach and grabbing products, stores or shops, particularly in big cities where fresh food like fruit and vegetables is difficult to be self-sufficient. According to Carr [48], the result of this circumstance being that citizens have stored such a vast quantity for a long period that a significant volume of food will be out of date and will have to be wasted. Study findings indicate that the risk assessment of the COVID-19 pandemic has positively influenced customer perceptions towards the intention to hold food in storage, and has consequently influenced the intention to store food by Bangladeshi consumers. As an example, let a tsunami cause all the people to start to reserve food across capital cities, and try to collect foods and other necessary things that they need to survive that period. Here a similar situation arises during COVID-19. They stock food for survival even if the outdated products as a whole city is under lockdown. It indicates that buying behaviour is highly affected by market perception as shown in the research [49-50]. All hypotheses are supported in this analysis. The expected behaviour attribute has a significant effect on the desire to stockpile during the pandemic.

In conclusion, the main challenge for policymakers is that individuals are still influenced by their emotions and confidence in bad events that might arise in the future. The rising buying of hoarding products renders shelves bare in supermarkets. When the expected behaviour of customers is affected by attitudes, subjective norms, and risk perception, their propensity to store food during the pandemic may also increase, even as they are conscious of market uncertainty and other effects of hoarding. Throughout the social instability of the community, such as the current pandemic, the government can mitigate people's perceived behaviour with effective measures, such as allowing goods available throughout stores, implement strategies to avoid unregulated demand inflation and price rises, and improve cooperation to convince consumers not to purchase so many reserve commodities. Two classes of citizens with two contrasting views will emerge in the pandemic exacerbated by COVID-19. Many individuals are very thoughtless with alarming details regarding the occurrence with dangerous disease, unaware of epidemic alerts. 


\section{DECLARATION OF CONFLICT OF INTEREST}

The authors received no financial support for the research and/or authorship of this article. There is no conflict of interest.

\section{REFERENCES}

1. Spagnuolo G, De Vito D, Rengo S, Tatullo M. COVID-19 Outbreak: An Overview on Dentistry. 2020: 2094. (doi: 10.3390/ijerph17062094). PMid:32235685 PMCid: PMC7143628

2. Chen N, Zhou M, Dong X, Qu J, et al. Epidemiological and clinical characteristics of 99 cases of 2019 novel coronavirus pneumonia in Wuhan, China: a descriptive study. The Lancet. 2020 Feb 15; 395(10223): 507-13. (doi: 10.1016/S0140-6736(20)30211-7).

3. Meng L, Hua F, Bian Z. Coronavirus disease 2019 (COVID19): emerging and future challenges for dental and oral medicine. Journal of Dental Research. 2020 Mar 12: 0022034520914246. (doi: 10.1177/0022034520914246). PMid:32162995 PMCid:PMC7140973

4. Peng X, Xu X, Li Y, Cheng L, Zhou X, Ren B. Transmission routes of 2019-nCoV and controls in dental practice. International Journal of Oral Science. 2020 Mar 3; 12(1): 1-6. (doi: 10.1038/s41368-020-0075-9). PMid:32127517 PMCid:PMC7054527.

5. Mulenga EM, Marbán JM. Is COVID-19 the Gateway for Digital Learning in Mathematics Education? Contemporary Educational Technology, 2020; 12(2): ep269. (doi: 10.30935/cedtech/7949).

6. Woods A. Iceland scientists found 40 mutations of the coronavirus, report says. NYPost. March 24, 2020.

7. Worldometers. (2020). COVID-19 Coronavirus Pandemic. Available at: https://www.worldometers.info/ coronavirus

8. Hossain A, Rana J, Benzadid S, Ahsan GU. Covid-19 and Bangladesh. 2020 March. (doi: 10.13140/ RG.2.2.33293.08161).

9. Worldometers.info, Dover, Delaware, U.S.A [cited 13 April 2020]. Available at: http://www.worldometers.info/ coronavirus/\#countries

10. Huff AG, Beyeler WE, Kelley NS, McNitt JA. How resilient is the United States' food system to pandemics? J. Environ. Stud. Sci. 2015; 5: 337-47.
11. Galanakis CM. The Food Systems in the Era of the Coronavirus (COVID-19) Pandemic Crisis. Foods 2020, 9, 523. (doi: 10.3390/foods9040523).

12. Galanakis CM. Recovery of high added-value components from food wastes: Conventional, emerging technologies and commercialized applications. Trends in Food Science \& Technology, 2012; 26(2): 68-87. (doi: 10.1016/j.tifs.2012.03.003).

13. Deng Q, Zinoviadou KG, Galanakis CM, Orlien V, et al. The Effects of Conventional and Non-conventional Processing on Glucosinolates and Its Derived Forms, Isothiocyanates: Extraction, Degradation, and Applications. Food Engineering Reviews, 2015; 7(3): 35781. (doi: 10.1007/s12393-014-9104-9).

14. Galanakis CM. Emerging technologies for the production of nutraceuticals from agricultural by-products: A viewpoint of opportunities and challenges. Food and Bioproducts Processing, 2013; 91(4): 575-9. (doi: 10.1016/j.fbp.2013.01.004).

15. Long NN, Khoi BH. An Empirical Study about the Intention to Hoard Food during COVID-19 Pandemic. EURASIA J Math Sci Tech Ed. 2020; 16(7): em1857. (doi: 10.29333/ejmste/8207).

16. Bloom E, De Wit V, Carangal-San Jose MJ. Potential economic impact of an avian flu pandemic on Asia. Asian Development Bank. 2005. Available at: https://www.adb.org/sites/default/files/publication/280 82/pb042.pdf

17. Cooper M. Japanese tourism and the SARS epidemic of 2003. Journal of Travel \& Tourism Marketing, 2006; 19(23): 117-31. (doi: 10.1300/J073v19n02_10).

18. Deng Y, Wang M, Yousefpour R. How do people's perceptions and climatic disaster experiences influence their daily behaviors regarding adaptation to climate change? A case study among young generations. Science of the total environment, 2017; 581: 840-7. (doi: 10.1016/j.scitotenv.2017.01.022).

19. Wen Z, Huimin G, Kavanaugh RR. The impacts of SARS on the consumer behaviour of Chinese domestic tourists. Current Issues in Tourism, 2005; 8(1): 22-38. (doi: 10.1080/13683500508668203).

20. Usak M, Masalimova RA, Cherdymova IE, Shaidullina RA. New playmaker in science education: Covid-19. Journal of Baltic Science Education, 2020; 19(2): 180-5. (doi: 10.33225/jbse/20.19.180). 
21. Basilaia G, Kvavadze D. Transition to Online Education in Schools during a SARS-CoV-2 Coronavirus (COVID-19) Pandemic in Georgia. Pedagogical Research, 2020; 5(4): em0060. (doi: 10.29333/pr/7937).

22. Toquero CM. Challenges and Opportunities for Higher Education amid the COVID-19 Pandemic: The Philippine Context. Pedagogical Research, 2020; 5(4): em0063. (doi: 10.29333/pr/7947).

23. Mulenga EM, Marbán JM. Is COVID-19 the Gateway for Digital Learning in Mathematics Education?. Contemporary Educational Technology, 2020; 12(2): ep269. (doi: 10.30935/cedtech/7949).

24. Long NN, Khoi BH. An Empirical Study about the Intention to Hoard Food during COVID-19 Pandemic. Eurasia Journal of Mathematics, Science and Technology Education, 2020; 16(7): em1857. (doi: 10.29333/ejmste/8207).

25. Papapicco C. Informative Contagion: The Coronavirus (COVID-19) in Italian journalism. Online Journal of Communication and Media Technologies, 2020; 10(3): e202014. (doi: 10.29333/ojcmt/7938).

26. Gondauri D, Batiashvili M. The Study of the Effects of Mobility Trends on the Statistical Models of the COVID19 Virus Spreading. Electron J Gen Med. 2020; 17(6): em243. (doi: 10.29333/ejgm/8212).

27. Ajzen I. The Theory of Planned Behaviour. Organised Behaviour and Human Decision Processes, 1991; 50: 170211.

28. Ajzen I, Driver BL. Application of the theory of planned Behaviour to leisure choice. Journal of Leisure Research, 1992; 24: 207-585.

29. Ajzen I, Fishbein M. Understanding attitudes and predicting social behavior. Englewood Cliffs, NJ: Prentice Hall; 1980.

30. Johnson EJ, Tversky A. Affect, generalization, and the perception of risk. Journal of personality and Social Psychology, 1983; 45(1): 20. (doi: 10.1037/00223514.45.1.20).

31. Lo AY. The role of social norms in climate adaptation: Mediating risk perception and flood insurance purchase. Global Environmental Change, 2013; 23(5): 1249-57. (doi: 10.1016/j.gloenvcha.2013.07.019).
32. Lobb A, Mazzocchi M, Traill W. Modelling risk perception and trust in food safety information within the theory of planned behaviour. Food quality and preference, 2007; 18(2): 384-95. (doi: 10.1016/j.foodqual.2006.04.004).

33. Kozup J. Risks of Consumer Products Consumer Perception of Product Risks and Benefits. Springer, 2017. p. 23-38. https://doi.org/10.1007/978-3-319-50530-5_2

34. Jacoby J, Kaplan LB. The components of perceived risk. ACR Special Volumes. 1972.

35. Oltedal S, Moen B-E, Klempe H, Rundmo T. Explaining risk perception: An evaluation of cultural theory. Trondheim: Norwegian University of Science and Technology, 2004; 85(1-33): 86.

36. Knight FH. Risk, uncertainty and profit: Courier Corporation, 2012

37. Dowling GR, Staelin R. A model of perceived risk and intended risk-handling activity. Journal of consumer research, 1994; 21(1): 119-34. (doi: 10.1086/209386).

38. Lobb A, Mazzocchi M, Traill W. Modelling risk perception and trust in food safety information within the theory of planned behaviour. Food quality and preference, 2007; 18(2): 384-95. (doi: 10.1016/j.foodqual.2006.04.004).

39. Hamdah DFL, Rahmadya RR, Nurlaela L. The Effect of Attitude, Subjective Norm, and Perceived Behavior Control of Taxpayer Compliance of Private Person in Tax Office Garut, Indonesia. Review of Integrative Business and Economics Research, 2020; 9: 298-306.

40. Huynh G, Nguyen TNH. Knowledge and attitude toward COVID-19 among healthcare workers at District 2 Hospital, Ho Chi Minh City. Asian Pacific Journal of Tropical Medicine, 2020. (doi: 10.4103/19957645.280396).

41. Van Bavel JJ, Boggio P, Capraro V, Cichocka A, Cikara M, Crockett $M$, et al. Using social and behavioural science to support COVID-19 pandemic response. 2020. (doi: 10.31234/osf.io/y38m9).

42. Sowden S, Koletsi S, Lymberopoulos E, Militaru E, Catmur C, Bird G. Quantifying compliance and acceptance through public and private social conformity. Consciousness and cognition, 2018; 65: 359-67. (doi: 10.1016/ j.concog.2018.08.009). 
43. Dickie R, Rasmussen S, Cain R, Williams L, Mackay W. The effects of perceived social norms on handwashing behaviour in students. Psychology, health \& med, 2018; 23(2): 154-9. (doi: 10.1080/13548506.2017.1338736).

44. Deng Y, Wang M, Yousefpour R. How do people's perceptions and climatic disaster experiences influence their daily behaviors regarding adaptation to climate change? A case study among young generations. Science of the total environment, 2017; 581: 840-7. (doi: 10.1016/j.scitotenv.2017.01.022).

45. Danks NP, Sharma PN, Sarstedt M. Model selection uncertainty and multimodel inference in partial least squares structural equation modeling (PLS-SEM). Journal of Business Research, 2020; 113: 13-24. (doi: 10.1016/j.jbusres.2020.03.019).

46. Hair Jr JF, Hult GTM, Ringle C, Sarstedt M. A primer on partial least squares structural equation modeling (PLSSEM): Sage Publications. 2016. (doi: 10.15358/9783800653614).
47. Klesel M, Schuberth F, Henseler J, Niehaves B. A test for multigroup comparison using partial least squares path modeling. Internet research, 2019; 29(3): 464-77. (doi: 10.1108/ IntR-11-2017-0418).

48. Carr J. 'The madness continues': Social media users slam 'wasteful' panic-buyers who are still throwing away perfectly good food after stockpiling more than they can consume. MAILONLINE. 2020. Available at: https://www. dailymail.co.uk/news/article-8168489/Social-media users-slam-wasteful-panic-buyers-throwing-away perfectly-good-food.html

49. Lobb A, Mazzocchi M, Traill W. Modelling risk perception and trust in food safety information within the theory of planned behaviour. Food quality and preference, 2007; 18(2): 384-95. (doi: 10.1016/j.foodqual.2006.04.004).

50. Quintal VA, Lee JA, Soutar GN. Risk, uncertainty and the theory of planned behavior: A tourism example. Tourism Management, 2010; 31(6): 797-805. (doi: 10.1016/j.tourman.2009.08.006). 